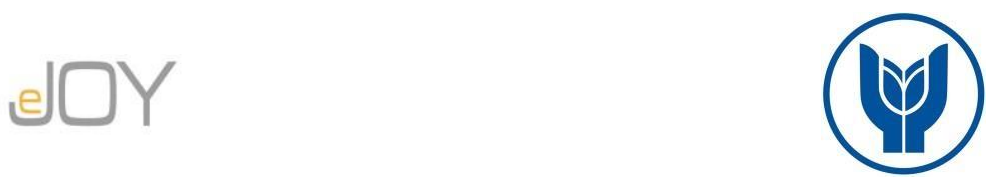

Kılıç, E., Gürsoy, S., Ergüney, E. B. / Journal of Yasar University, 2021, 16/64, 1592-1604

\title{
Bitcoin Elektrik Tüketimi ile Enerji Piyasaları Arasında Volatilite Yayılımı: Seçili Ülkelerden Kanıtlar
}

\section{Volatility Spillover Between Bitcoin Electricity Consumption and Energy Markets: Evidence From Selected Countries}

\author{
Ethem KILIÇ, Bingöl Üniversitesi, Türkiye, etemklc@ hotmail.com
}

Orcid No: 0000-0002-6247-9024

Samet GÜRSOY, Burdur Mehmet Akif Ersoy Üniversitesi, Türkiye, sametgursoy@mehmetakif.edu.tr

Orcid No: 0000-0003-1020-7438

Enes Burak ERGÜNEY, Burdur Mehmet Akif Ersoy Üniversitesi, Türkiye, enesburakergney@gmail.com

Orcid No: 0000-0003-1538-1489

Öz: Bu çalışmada, Bitcoin elektrik tüketiminin, Bitcoin üretiminde önde gelen seçili ülkelerin enerji piyasaları ile arasındaki ilişki araştırılmıştır. Çalışmada 22.05.2017-10.02.2021 dönemine ait haftalık veriler kullanılmıştır. Cambridge Bitcoin Elektrik Tüketim Endeksi (CBECI) ile S\&P 500, MOEX ve SSE enerji endeksleri arasındaki volatilite hareketleri CCC-GARCH modeliyle analiz edilmiştir. CCC-GARCH modelinde elde edilen bulgulara göre CBECI endeksinin MOEX enerji endeksi ile arasında çift yönlü volatilite yayılımı olduğu, S\&P 500 ve SSE enerji endeksleri ile arasında tek yönlü bir volatilite yayılımı olduğunu belirlenmiştir. S\&P 500 enerji endeksinden meydana gelen şokların CBECI endeksini artırdiğ endeksinden meydana gelen şokların ise CBECI endeksini azalttığl tespit edilmiştir.

Anahtar Kelimeler: Bitcoin, Elektrik Tüketimi, Enerji Piyasaları, CCC GARCH

JEL Sinıflandırmast: G10, Q40, Q43

Abstract: In this study, the relationship between Bitcoin electricity consumption and the energy markets of selected countries leading in Bitcoin production was investigated. Weekly data for the period 22.05.201710.02.2021 were used in the study. The volatility movements between the Cambridge Bitcoin Electricity Consumption Index (CBECI) and the S\&P 500, MOEX and SSE energy indices were analyzed with the CCCGARCH model. According to the findings obtained in the CCC-GARCH model, it has been determined that there is a bidirectional volatility spread between the CBECI index and the MOEX energy index, and a unidirectional volatility spread between the S\&P 500 and SSE energy indices. It has been determined that shocks from the $S \& P$ 500 energy index increase the CBECI index, but shocks from the MOEX energy index decrease the CBECI index.

\section{Keywords: Bitcoin, Electricity Consumption, Energy Markets, CCC GARCH}

JEL Classification: G10, Q40, Q43

\section{Giriş}

Kripto paralar şifreli olarak yapılan işlemlerin güvenliğini sağlayan; nakit ve merkezi para birimlerine alternatif olarak, dijital ve bağımsız olan varlıklardır. Herhangi bir otoritenin düzenleme ve denetlemesine tabi olmayan kripto paralar, merkezi paradan kaçışın en iyi örneklerindendir. Kripto paraların bir otoriteye bağlı olmaması ve işleyiş için aracı kurumlara ihtiyaç duyulmaması muhtemel riskleri indirgemekte ve kurumlara güvenme gereksinimini ortadan kaldırmaktadır. İşleyişin Blokzincir (Blokchain) teknolojisi ile sürdürüldüğü sistem sayesinde şeffaflık ve iş ispatı sağlanmaktadır (Çarkacıoğlu 2016, 8-10). 
Blockchain teknolojisinin kullanıldığı ve merkezi otoritenin bulunmadığı ilk kripto para olma unvanını taşıyan Bitcoin (BTC), Satoshi Nakamoto kod adıyla yazılan "Bitcoin: Uçtan Uca Elektronik Ödeme Sistemi (2008) “isimli makale ile dünyaya duyurulmuştur. Günümüzde birçok kripto para bulunmasına rağmen, Bitcoin en popüler kripto para olmayı sürdürmektedir. Elde ettiği popülarite sayesinde kullanımı hızla yayılan Bitcoin, 2018 yılında CME Group ve Chicago Board Options Exchange'in (CBOE) şirketleri aracılığıyla ABD vadeli işlem piyasalarında işlem görmeye başlamıştır (Gurrib 2019, 3).

Bitcoin'i elde etmenin üç yöntemi bulunmaktadır. Bunlardan birincisi; çeşitli kurumlar aracılığıyla doğrudan satın alma, ikincisi; ticari faaliyetler ve satış sonucunda kazanç olarak elde etme ve üçüncüsü ise kripto para madenciliği yoluyla üretmektir. Madencilik yoluyla Bitcoin üretimi, açık kaynak kodlu yazılımlar sayesinde blok oluşturarak, oluşan bloktaki problemlerin çözülmesi sonucu madencinin ödüllendirilmesi ile sağlanır.

Günümüzde madenci Bitcoin ödülünü elde edebilmek için yüksek düzeyde enerji harcayarak iş ispatını gerçekleştirmesi gerekir. Madencinin harcadığı enerji, Bitcoin'in doğrudan ve dolaylı olarak elektrik tüketimini oluşturan 4 faktörden kaynaklanmaktadır (Kamiya, 2019):

\section{Madencilik donanımların elektrik tüketimi}

2. A ̆g hashrate, ağdaki tüm madencilerin eşzamanlı olarak problemin çözümlerini tahmin ettiği birleşik oran

3. Her 10 dakikada bir bloğun hedef blok oranını korumak için ağ karma oranına yanıt olarak ayarlanan problemi çözmenin zorluk derecesi

4. Soğutma ve aydınlatma gibi gereksinimlerin elektrik tüketimi

Bitcoin'in küresel elektrik tüketimindeki \%0,63 payı (IEA, 2016) söz konusu tüketimin önemini ortaya koymaktadır. Kesin olarak hesaplanamayan tüketimin, tahmini olarak belirlenmesi için ise çeşitli çalışmalar bulunmaktadır. Literatürde kabul görmüş çalışmalardan biri olan Cambridge Bitcoin Elektrik Tüketim Endeksi (CBECI), Bitcoin ağının toplam elektrik yükü ve tüketiminin gerçek zamanlı bir tahminini sağlamaktadır. CBECI bir alt sınır (taban) ve bir üst sınır (tavan) tahmininden oluşan bir dizi olasılığı kapsamaktadır. Alt sınır tahmini, tüm madencilerin her zaman piyasadaki elektrik tüketimi açısından en verimli ekipmanı kullandığı en iyi durum varsayımına dayanan, minimum toplam elektrik harcamasına karşılık gelmektedir. Üst sınır tahmini ise, tüm madencilerin elektrik açısından karlı olduğu sürece, elektrik tüketimi açısından piyasadaki en az verimli donanımı kullandığı en kötü durum varsayımına dayalı olarak, maksimum toplam elektrik harcamasını belirtmektedir. $\mathrm{Bu}$ aralığın sınırları içinde, küresel ortalama elektrik fiyatları baz alınarak 
Bitcoin'in gerçek elektrik tüketimine en yakın olabilecek, daha gerçekçi tahmin hesaplanmaktadır (Rauchs vd., 2020).

$\mathrm{Bu}$ çalışmada, Bitcoin'in elektrik tüketimi ile Bitcoin madenciliğinin yaygın olduğu seçili ülkelerin önde gelen enerji piyasası endeksleri arasındaki volatil hareketlerin incelenmesi amaçlanmaktadır. İlgili literatürde Bitcoin'in elektrik tüketimine ilişkin çalışmalarda madencilik karlılığı ve karbon ayak izi gibi konuların incelendiği, enerji piyasaları ve Bitcoin ilişkisine yönelik çalışmaların ise Bitcoin fiyatları ile gerçekleştirildiği görülmüştür. Ancak bu çalışmada, birçok yönden yadsınamayacak değere sahip Bitcoin'in enerji piyasaları ile ilişkisi, literatürden farklı olarak Bitcoin'in elektrik tüketimi incelenmiş ve bu yönüyle literatüre katkıda bulunması umulmuştur.

Amaç doğrultusunda çalışmanın giriş bölümünü takiben, birinci bölümünden sonra ikinci bölümünde konu ile ilişkili çalışmaların yer aldığı literatür özetine ve üçüncü bölümde ise çalışmanın metodolojisine ve analiz sonuçlarında elde edilen bulgulara yer verilmiştir. Sonuç bölümünde ise çalışmadan elde edilen ampirik bulgular, konuya ilişkin literatür çerçevesinde değerlendirilmiş ve yorumlanmıştır.

\section{Literatür Özeti}

Literatürde yaygın bir yer kaplayan Bitcoin üzerine, farklı kapsamlarda ve çeşitli konularda çalışmalar bulunmaktadır. Enerji yoğun bir ağ üzerinden çalışması sebebiyle, Bitcoin ve enerji ilişkisi de literatürde sıkça karşılaşılan konulardandır. $\mathrm{Bu}$ konuda yapılan çalışmalar incelendiğinde genellikle Bitcoin fiyatları ile enerji piyasaları, enerji emtia bileşenleri ve çeşitli enerji yatırımları çerçevesinde yoğunlaşıldığ 1 görülmektedir. Bununla birlikte Bitcoin üretiminin temel girdisini oluşturan elektrik tüketimi ile yapılan çalışmaların kısıtlı olduğu ve genel olarak madencilik karlılı̆̆ ve karbon ayak izi konularından oluştuğu gözlemlenmektedir. Söz konusu çalışmalarda genellikle Genelleştirilmiş Otoregresif Koşullu Değişen Varyans (GARCH) modellerinin kullanılmıştır. Bu çalışma, Bitcoin’in elektrik tüketimine odaklanılması ve seçili ülkelerin enerji sektör endeksleri ile arasındaki ilişkinin araştırılması açısından literatürden farklılaşmaktadır.

Bouri vd. (2017) çalışmalarında Bitcoin' in, emtia volatilitesine karşı bir hedge aracı olabilirliğini araştırmışlardır. Bu kapsamda 18.07.2010-28.12.2015 tarihleri arasında günlük veriler kullanılarak; Bitcoin fiyatları ile S\&P genel emtia endeksi (S\&P GSCI), S\&P GSCI enerji emtia endeksi ve S\&P GSCI enerji dışı emtia endeksi arasındaki ilişki incelenmiştir. DCC GARCH modeli ile 2013 Bitcoin çöküşü öncesi, sonrası ve tüm dönem olmak üzere üç döneme ayrılarak yapılan analiz sonucunda; tüm dönem ve 2013 çöküşü öncesi dönem 
boyunca Bitcoin' in S\&P emtia ve enerji emtia endekslerine karşı güçlü bir koruma gösterdiği gözlemlenmiştir. Ancak enerji dışı emtia endeksine karşı önemsiz bulgular, genel emtia endeksindeki ilişkinin enerji emtia bileşenlerinden kaynaklandığı sonucuna ulaştırmıştır. Bununla birlikte 2013 çöküşü sonrası dönemde, Bitcoin' in bütün endekslere karşı koruma yetisini kaybettiği, bir hedge aracı niteliği taşımadığı saptanmıştır.

Symitsi ve Chalvatzis (2018) çalışmalarında, Bitcoin ile enerji ve teknoloji şirketleri arasındaki yayılma etkilerini araştırmışlardır. Bu kapsamda 22.08.2011-15.02.2018 tarihleri arasında günlük veriler kullanılarak; Bitcoin fiyatları ile S\&P Küresel Temiz Enerji Endeksi (SPGCE), MSCI Dünya Enerji Endeksi (MSCIWE) ve MSCI Dünya Bilgi Teknolojisi Endeksi (MSCIWIT) arasındaki yayılma ilişkisi incelenmiştir. VAR-BEKK-AGARCH modeli ile yapılan analiz sonucunda, enerji ve teknoloji hisse senedi endekslerinden Bitcoin' e önemli geri dönüş yayılımları gözlemlenmiştir. Ayrıca, Bitcoin' in enerji şirketleri üzerinde uzun vadeli volatilite etkileri saptanmış; Bitcoin ve hisse senedi endeksleri arasında çift yönlü asimetrik şok yayılmaları tespit edilmiştir.

Baur ve Oll (2019) çalışmalarında, Bitcoin fiyatları ile enerji fiyatları arasındaki ilişkiyi araştırmışlardır. Bu kapsamda 01.2009-01.2019 tarihleri arasında aylık veriler kullanılarak; Bitcoin fiyatları ile kömür fiyatları (ICE), ham petrol fiyatları (WTI), S\&P 500 Enerji Şirketleri Endeksi (S\&P 500 EW Energy), MSCI Dünya Enerji Endeksi ve çeşitlendirilmiş temiz enerji endeksi (Wilderhill temiz enerji endeksi) arasındaki ilişki incelenmiştir. Üç gecikmeli (ay) bir VAR modeli ile yapılan analiz sonucunda, Bitcoin madenciliğinin enerji tüketiminin enerji şirketi değerlemelerini etkilediğini ve bunun da Bitcoin fiyatlarını etkilediği gözlemlenmiştir. Ayrıca, Bitcoin fiyat değişiklikleri ile kömür fiyatı değişiklikleri arasında 0.21 olarak tahmin edilen güçlü eşzamanlı korelasyon ve Bitcoin ile petrol arasında 0.17 olarak tahmin edilen daha zayıf ve istatistiksel olarak önemsiz bir korelasyon saptanmıştır.

Gurrib vd. (2020) çalışmalarında, enerji blok zinciri tabanlı kripto para birimlerinin, ABD S\&P Composite 1500 enerji endeksinin önde gelen enerji şirketlerinden oluşan hisse senedi portföylerini çeşitlendirmeye yardımcı olup olamayacağını araştırmışlardır. Bu kapsamda 21.11.2017-31.01.2019 tarihleri arasında günlük veriler kullanılarak; seçili kripto paraların (SNC, POWR, TSL, GRID) günlük kapanış fiyatları ile S\&P Kompozit 1500 enerji endeksinde işlem gören ilk on enerji hissesi arasındaki ilişki incelenmiştir. ARIMA-GARCH modeli ile yapılan analiz sonucunda, farklı risk önlemlerinin kullanılmasına rağmen enerji bazlı kripto paraların, enerji hisse senedi portföyleri üzerinde önemli bir etkiye sahip olmadığı gözlemlenmiştir. Yazarlar bu durumu, önde gelen ABD enerji şirketlerine dayanan 
portföylerin verimliliğine göre, enerji kriptolarının nispeten zayıf performansına atfetmişlerdir.

Rehman ve Kang (2020) çalışmalarında, Bitcoin hashrate ve enerji emtia piyasaları arasında bir zaman-frekans değişimi ve nedensellik ilişkisini araştırmışlardır. Bu kapsamda 01.01.2013-12.10.2018 tarihleri arasında günlük veriler kullanılarak; Bitcoin fiyatları ve hash oranını ile seçili enerji emtia bileşenleri (petrol, gaz, kömür) arasındaki ilişki incelenmiştir. Kısmi ve çok değişkenli dalgacık modelleri ile yapılan analizlerin sonucunda, enerji emtia bileşenlerinin Bitcoin fiyatları ve hash oranı arasındaki ilişkiyi etkilediği gözlemlenmişstir. Bununla birlikte, Bitcoin fiyatları ve hash oranının uzun vadede, petrol ve gaz fiyatları ile yüksek korelasyon içindeyken, kömür fiyatları ile ilişkisinin olmadığı saptanmıştır.

Doruk (2021) elektrik sektörü ile döviz kuru - hisse senedi fiyatı arasındaki ilişkiyi incelemiştir. Ocak 2009 - Aralık 2019 dönemini kapsayan veriler ile ARDL modeli ile araştırma gerçekleşmiştir. Elektrik sektörü ile döviz kuru arasında kısa vadede ilişki tespit edilmiş, ancak uzun vadede ilişkiye rastlanılmamıştır.

Delgado-Mohatar vd. (2019) Bitcoin ağının enerji tüketiminin güncel bir tahminini ve zaman içinde Bitcoin üretim maliyetinin gelişiminin hesaplanması araştırmışlardır. Haziran 2018 tarihinde Bitcoin madenciliği için bir dönüm noktası olduğu belirlenmiştir. Bu dönemde öncesinde bitcoin madenciliği, fiyatları marjinal maliyetinin altına düştüğü için elektrik maliyetleri 0.14 \$/kWh'nin üzerinde olan madenciler için karlı olmadığı tahmin edilmiştir.

Huynh vd. (2021) enerji tüketimi ve Bitcoin piyasası arasındaki ilişkiyi ele almışlardır. Günlük veriler ile gerçekleşen yarı varyanslarla birlikte varyans ayrıştırmalarını kullanarak, Bitcoin enerji tüketimi ile getirileri ve hacimleri arasında ilişkiyi araştırmışlardır. Bitcoin ticaret hacimlerinin enerji tüketimi uzun vadede etkili olduğu bulgusunu elde etmişlerdir.

Güven ve Bulut (2021) çalışmalarında Bitcoin ve emtia ilişkisini araştırmışlardır. Bu kapsamda Ocak 2012- Mart 2020 tarihleri arasında cumhuriyet altını, altın ons fiyatı, ham petrol fiyatı, amerikan doları ve euro para birimleri ile bitcoin arasındaki korelasyon ilişkisini incelenmişlerdir. Araştırma kapsamında Spearman korelasyon analizinden faydalanmışlardır. Analizlerin sonucuna göre, piyasalara girdiği ilk dönem olan 2012'de bitcoinin diğer göstergelerle arasında istatistiksel olarak anlamlı ilişki bulamamışlardır.

\section{Metodoloji}

ARCH ve GARCH modelleri tek değişkenli finansal varlıkların volatil hareketlerin incelemesinde kullanılmaktadır. ARCH ve GARCH modelleri değişen koşullu varyans modellerini tahmin etmektedir. ARCH ve GARCH modelleri birden fazla finansal varlıkların 
modellenmesinde yetersiz kalmaktadır. Finansal piyasaların küreselleşmesinden dolayı finansal piyasalar arasında etkileşimler de artmıştır. Bu nedenle çok değişkenli GARCH modelleri önem kazanmıştır.

Çok değişkenli GARCH modelleri finans literatürden oldukça önem arz etmektedir. Finansal değişkenlere ait volatil etkileşimleri incelemek için yoğun olarak kullanılan GARCH modelleri; Vektör Hata Düzeltme (VECH) modeli, Baba, Engle, Kraft ve Kroner (BEKK) modeli, Dinamik Koşullu Korelasyon (DCC) modeli ve Sabit Koşullu Korelasyon (CCC) şeklinde belirtmek mümkündür. VECH, BEKK, DCC ve CCC modellerinde ortalama denklemlerin tanımları aynıdır. Ancak koşullu varyansın tahmini sürecinde koşullar farklılık göstermektedir (Demirgil ve Kesekler 2019, 1169).

Tek bir finansal varlığın risk yapısının incelenmesinde kullanılan ARCH ve GARCH modellerinin Bollerslev, Engle ve Wooldridge (1988), tarafindan VEC parametrizasyonu çözüm tekniğiyle geliştirilerek birden fazla zaman serisi için geliştirilmesi, VEC-GARCH modeli olarak adlandırılan çok değişkenli GARCH modellemesini oluşturmuştur. VEC parametrizasyonundan kaynaklanan bazı sorunlardan dolayı Engle ve Kroner (1995)'in çok değişkenli GARCH modellerinde BEKK modellini geliştirmişlerdir. Bollerslev (1990) ise çok değişkenli GARCH modelinin çözümünde koşullu varyansın yanı sıra koşullu korelasyonu da dikkate alan CCC-GARCH modelini geliştirmiştir (Hepsağ ve Akçalı 2016, 57).

$$
\begin{aligned}
& y_{A, t}=\sqrt{h_{A, t} \varepsilon_{A, t}} \\
& y_{B, t}=\sqrt{h_{B, t} \varepsilon_{B, t}} \\
& \rho_{t}=\operatorname{cov}\left(\varepsilon_{A, t}, \varepsilon_{B, t}\right) \\
& {\left[\begin{array}{l}
h_{A, t} \\
h_{B, t}
\end{array}\right]=\left[\begin{array}{l}
c_{1} \\
c_{2}
\end{array}\right]+\left[\begin{array}{ll}
\alpha_{11} & \alpha_{12} \\
\alpha_{21} & \alpha_{22}
\end{array}\right]\left[\begin{array}{l}
y_{A, t-1}^{2} \\
y_{B, t-1}^{2}
\end{array}\right]+\left[\begin{array}{ll}
b_{11} & b_{12} \\
b_{21} & b_{22}
\end{array}\right]\left[\begin{array}{l}
h_{A, t-1} \\
h_{B, t-1}
\end{array}\right]}
\end{aligned}
$$

CCC-GARCH modeli her bir finansal varlığın volatilitesi hakkında bilgi verdiği gibi finansal varlıkları arasındaki volatilite etkileşimi hakkında da bilgi vermektedir. $\rho_{\mathrm{t}}$ Finansal varlıkların getiri arasındaki sabit korelasyonları hakkında bilgi vermektedir. Yani getirilerin birbiriyle etkileşimini ölçmektedir.

CCC-GARCH modelinde, A finansal varlığına ait volatilitenin kalıcılı̆̆ı hakkında bilgi veren $\alpha_{11}$ ve $b_{11}$ parametreleridir. B finansal varlığına ait volatilitenin kalıcılığı ise $\alpha_{22}$ ve $b_{22}$ parametreleri ile ölçülmektedir. $\alpha_{11}, b_{11}, \alpha_{22}$ ve $b_{22}$ parametrelerinin anlamlı olmalı ve değerlerinin toplamının 1'e yakın olmalıdır. $\alpha_{12}$ ve $b_{12}$ parametreleri ise volatilite etkileşimi hakkında bilgi sunmaktadır. B finansal varlıktan A finansal varlığına doğru volatilite etkileşiminin olduğunu söyleyebilmek için parametrelerin istatiski açından anlamlı olması 
gerekmektedir. $\alpha_{21}$ ve $b_{21}$ parametrelerinin anlamlı olması durumunda A finansal varlıktan A finansal varlığına doğru volatilite etkileşimi olduğu söylenebilir.

\section{Veri Seti ve Değişkenler}

Çalışmada kullanılan değişkenlere ilişkin tanımlamalar Tablo 1'de verilmiştir.

Tablo 1. Ekonometrik Analizde Kullanılacak Değişkenler ve Veri Kaynakları

\begin{tabular}{|l|c|c|c|}
\hline Değişken & Değişken Açıklaması & $\begin{array}{c}\text { Zaman Aralı̆̆ } \\
\text { Veri Periyodu }\end{array}$ & Kaynak \\
\hline CBECI & Bitcoin Elektrik Tüketimi & $\begin{array}{c}22.05 .2017- \\
10.02 .2021\end{array}$ & cbeci.org \\
\hline MOEX & Endeksi & $22.05 .2017-$ & \\
Enerji & Rusya'nın enerji piyasaları & 10.02 .2021 & Investing.com \\
\hline S\&P 500 & ABD'nin enerji piyasaları & $\begin{array}{c}22.05 .2017- \\
10.02 .2021\end{array}$ & Investing.com \\
Enerji & endeksi & $22.05 .2017-$ & Investing.com \\
\hline \multirow{2}{*}{ SSE Enerji } & Çin'in enerji piyasaları & 10.02 .2021 & \\
\end{tabular}

Çalışmada kullanılan değişkenler, ele alınan dönem ve değişkenlerin elde edildiği adresler Tablo 1'de verilmiştir. Bitcoin'in elektrik tüketimi temsil etmesi için literatürde birçok çalışma tarafından kabul gören CBECI endeksi kullanılmıştır. CBECI endeksine ait veriler cbeci.org adresinde tedarik edilmiştir. Enerji piyasalarını göstergesi olarak, en yüksek hash oranına sahip ilk 3 ülke olan Rusya, ABD ve Çin'in önde gelen enerji piyasalarından Rusya için MOEX Enerji endeksi, ABD için S\&P 500 Enerji endeksi ve Çin için SSE Enerji endeksi belirlenmiştir. Enerji piyasaları endeksleri investing.com'dan tedarik edilmiştir. Çalışmanın analizleri EWievs 9 ve WinRATS Pro 8.1 paket programları kullanılmıştır.

\section{Ampirik Bulgular}

Değişkenlere ilişkin tanımlayıcı istatistikleri Tablo 2'de verilmiştir.

Tablo 2. Değişkenlerin Getiri Serilerine Ait Tanımlayıcı İstatistikler

\begin{tabular}{|l|l|l|l|l|}
\hline & CBECI & S\&P 500 ENERJI & SSE ENERJI & MOEX ENERJI \\
\hline Ortalama & 0,0166 & $-0,0419$ & $-0,0355$ & 0,0282 \\
\hline Medyan & 0,2019 & 0,0000 & 0,0000 & 0,0380 \\
\hline Maksimum & 929,7559 & 15,1108 & 6,0981 & 7,1157 \\
\hline Minimum & $-924,9263$ & $-22,4172$ & $-8,8150$ & $-11,3918$ \\
\hline Std. Sapma & 149,8923 & 2,2729 & 1,3075 & 1,1402 \\
\hline Çarplklık & 0,0028 & $-1,1776$ & $-0,5448$ & $-1,7847$ \\
\hline Basıklık & 23,2437 & 22,1509 & 7,5687 & 22,9742 \\
\hline Jarque-Bera & 16033,7935 & 14566,4312 & 863,0964 & 16108,0964 \\
\hline Olasılık & 0,0000 & 0,0000 & 0,0000 & 0,0000 \\
\hline Gözlem & 939 & 939 & 939 & 939 \\
\hline
\end{tabular}


CBECI, S\&P 500 ENERJİ, SSE ENERJİ ve MOEX ENERJİ değişkenlerinin getiri serilerine ait tanımlayıcı istatistikler incelendiğinde; standart sapma değerlerinin getiri serilerinin ortalama değerlerine göre daha büyük olduğu görülmektedir. Jarque-Bera test istatistiğine bakıldığında getiri serilerinin normal dağılmadığı söylenebilir.

Tablo 3. Birim Kök Testleri Sonuçları

\begin{tabular}{|c|c|c|c|c|}
\hline & \multicolumn{2}{|c|}{$\begin{array}{c}\text { AumentedDickey- Fuller } \\
\text { (ADF) }\end{array}$} & \multicolumn{2}{c|}{ Phillips-Perron (PP) } \\
\hline & Sabitli & $\begin{array}{c}\text { Sabitlive } \\
\text { Trendli }\end{array}$ & Sabitli & Sabitli ve Trendli \\
\hline CBECI & $-17,7595$ & $-17,7780$ & $-303,1000$ & $-345,9713$ \\
\hline S\&P 500 ENERJI & $-9,2408$ & $-9,2366$ & $-33,0148$ & $-32,9994$ \\
\hline SSE ENERJI & $-30,2985$ & $-30,2851$ & $-30,3107$ & $-30,2972$ \\
\hline MOEX ENERJI & $-17,7336$ & $-17,7353$ & $-28,1267$ & $-28,1196$ \\
\hline & & Kritik Değerler & $-3,9679$ \\
\hline$\% 1$ & $-3,4372$ & $-3,9679$ & $-3,4372$ & $-3,4147$ \\
\hline$\% 5$ & $-2,8644$ & $-3,4147$ & $-2,8644$ & $-3,1295$ \\
\hline$\% 10$ & $-2,5684$ & $-3,1295$ & $-2,5684$ & \\
\hline
\end{tabular}

Değişkenlere ilişkin birim kök testleri sonuçları Tablo 3'te verilmiştir. Yapılan ADF ve PP birim kök testlerine göre değişkenlerin seviye değerlerinde durağa oldukları tespit edilmiştir.

Tablo 4. CBECI ve S\&P 500 ENERJİ Getirilerine ait CCC-GARCH Modeli Sonuçları

\begin{tabular}{|c|c|c|c|c|}
\hline & Katsayılar & Standart Hatalar & t-Ístatistikleri & Olasılık Değerleri \\
\hline$c_{1}$ & 1300,6174 & 81,5949 & $15,9399 *$ & 0,0000 \\
\hline$c_{2}$ & 0,0502 & 0,0085 & $5,9337 *$ & 0,0000 \\
\hline$a_{11}$ & $-0,0720$ & 0,0549 & $-1,3119$ & 0,1896 \\
\hline$a_{12}$ & 2,9530 & 2,7020 & 1,0929 & 0,2744 \\
\hline$a_{21}$ & 0,1093 & 0,0880 & 1,2427 & 0,2140 \\
\hline$a_{22}$ & 0,0446 & 0,0181 & $2,4629 * *$ & 0,0139 \\
\hline$b_{11}$ & 0,768206 & 0,008064 & $95,2635 *$ & 0,0000 \\
\hline$b_{12}$ & 0,6480 & 0,2569 & $2,5224 * *$ & 0,0117 \\
\hline$b_{21}$ & 0,0777 & 0,1193 & $-0,6518$ & 0,5145 \\
\hline$b_{22}$ & 0,8842 & 0,0149 & $59,5373 *$ & 0,0001 \\
\hline$\theta_{1}$ & 0,566763 & 0,151499 & $3,74103 *$ & 0,0001 \\
\hline$\theta_{2}$ & 0,1263 & 0,0179 & $7,0456^{*}$ & 0,0000 \\
\hline
\end{tabular}

Tablo 4'te CBECI ve S\&P 500 enerji endekslerinin getirilerine ait CCC-GARCH modeli sonuçlarına göre, CBECI endeksinin volatilite kalıcılığı hakkında bilgi veren $\alpha_{11}$ ve $b_{11}$ 
parametrelerinden sadece $\mathrm{b}_{11} \% 1$ anlamlılık düzeyinden istatistiki açıdan anlamlıdır. CBECI değişkeninden volatilite kümelemesi oluştuğu söylenebilir. S\&P 500 enerji değişkeni volatilitesinin kalıcılığ hakkında bilgi veren $\alpha_{22}$ ve $b_{22}$ parametrelerinin her ikisinin de $\% 5$ önem düzeyinde anlamlı olduğu tespit edilmiş ve parametrelerin toplamı 0,92 olarak tespit edilmiştir. Elde edilen bu değerin 1'e yakın olduğu ve volatilite kümelemesi oluştuğu görülmektedir. S\&P 500 enerji endeksinin volatilitesinin kalıcı olduğu saptanmıştır.

S\&P 500 enerji endeksinin volatilitesinden CBECI endeksinin volatilitesine doğru olan etkileşimin varlığını ifade eden $\alpha_{12}$ ve $b_{12}$ parametrelerinden sadece $b_{12}$ parametresinin anlamlı olduğu yani S\&P 500 enerji endeksinde meydana gelen bir şokun CBECI endeksini 0,64 oranında etkilediği tespit edilmiştir. CBECI endeksinin volatilitesinden S\&P 500 enerji endeksinin volatilitesine doğru etkileşimi ölçen $\alpha_{21}$ ve $b_{21}$ parametrelerinden her ikisinin de istatistiki açıdan anlamlı olmadığı tespit edilmiştir. CBECI ve S\&P 500 enerji endeksleri arasındaki volatil davranışlar dikkate alındığında S\&P 500 enerji endeksinden CBECI endeksine doğru tek yönlü volatilite etkileşimi olduğu görülmektedir. Ayrıca CBECI getirileri ile S\&P 500 enerji endeksi getirileri arasındaki sabit koşullu korelasyon ilişkisini açıklayan $\theta_{1}$ ve $\theta_{2}$ parametrelerinden her ikisinin de istatistiki açıdan anlamlı olduğu, buna göre sabit koşullu korelasyonun pozitif yönlü ve orta düzeyde kuvvetli bir ilişkisi olduğu gözlemlenmektedir.

Tablo 5. CBECI ve SSE ENERJI Getirilerine ait CCC-GARCH Modeli Sonuçları

\begin{tabular}{|c|c|c|c|c|}
\hline & Katsayılar & Standart Hatalar & t-Istatistikleri & Olasılık Değerleri \\
\hline$c_{1}$ & 1314,8014 & 236,2718 & 5,5648 & 0,0000 \\
\hline$c_{2}$ & 0,2329 & 0,0590 & 3,9496 & 0,0001 \\
\hline$\alpha_{11}$ & $-0,0674$ & 0,0580 & $-1,1619$ & 0,2453 \\
\hline$\alpha_{12}$ & 3,8924 & 4,3376 & 0,8974 & 0,3695 \\
\hline$\alpha_{21}$ & 0,0007 & 0,0004 & $1,7927 * *$ & 0,0730 \\
\hline$a_{22}$ & 0,1179 & 0,0236 & $4,9983^{*}$ & 0,0000 \\
\hline$b_{11}$ & 0,7681 & 0,0090 & $85,7559 *$ & 0,0000 \\
\hline$b_{12}$ & $-82,7664$ & 1839,0932 & $-0,0450$ & 0,9641 \\
\hline$b_{21}$ & $-0,3710$ & 0,2494 & $-1,4877$ & 0,1368 \\
\hline$b_{22}$ & 0,7935 & 0,0350 & $22,6588^{*}$ & 0,0000 \\
\hline$\theta_{1}$ & 0,5554 & 0,1595 & 3,4829 & 0,0005 \\
\hline$\theta_{2}$ & $-0,0045$ & 0,0257 & $-0,1767$ & 0,8597 \\
\hline
\end{tabular}


Tablo 5'te CBECI ve SSE enerjisi getirilerine ait CCC-GARCH modeli sonuçlarına göre, CBECI endeksinin volatilite kalıcılığı hakkında bilgi veren $\alpha_{11}$ ve $b_{11}$ parametrelerinden sadece $\mathrm{b}_{11} \% 1$ anlamlılık düzeyinden istatistiki açıdan anlamlıdır. CBECI değişkeninden volatilite kalıcılığı olduğu söylemek mümkündür. $\alpha_{22}$ ve $b_{22}$ parametreleri ise SSE enerji endeksinin volatilitesinin kalıcılığını ölçmektedir. $\alpha_{22}$ ve $b_{22}$ parametrelerinin her ikisinin de \%1 önem düzeyinde anlamlı olduğu tespit edilmiş ve parametrelerin toplamı 0,90 olarak tespit edilmiştir. Elde edilen bu değerin 1'e yakın olduğu ve volatilite kümelemesi oluştuğu görülmektedir. SSE enerji endeksinin volatilitesinin kalıcı olduğu söylenebilir.

SSE enerji endeksinin volatilitesinden CBECI endeksi volatilitesine doğru olan etkileşimin varlığını ifade eden $\alpha_{12}$ ve $b_{12}$ parametrelerinin her ikisinin de istatistiki açından anlamlı olmadığı tespit edilmiştir. Yani SSE enerji endeksinden CBECI endeksine doğru volatilite etkileşimi bulunmamaktadır. CBECI endeksi volatilitesinden SSE enerji endeksi volatilitesine doğru etkileşimi ölçen $\alpha_{21}$ ve $b_{21}$ parametrelerinden sadece $\alpha_{21}$ parametresinin \%10'a göre anlamlı olduğu tespit edilmiştir. Yani CBECI endeksinde meydana gelen bir dalgalanmanın SSE enerji endeksini etkilediğini söylemek mümkündür. CBECI ve SSE enerji endeksleri arasındaki volatil davranışlar dikkate alındığında CBECI endeksinden SSE enerji endeksine doğru tek yönlü volatilite etkileşimi olduğu görülmektedir. Ayrıca CBECI getirileri ile SSE enerji getirileri arasındaki sabit koşullu korelasyon ilişkisini açıklayan $\theta_{1}$ ve $\theta_{2}$ parametrelerinden sadece $\theta_{1}$ istatistiki açıdan anlamlı olduğu buna sabit koşullu korelasyonun pozitif yönlü ve orta düzeyde kuvvetli bir ilişki bulunmaktadır.

Tablo 6. CBECI ve MOEX ENERJİ Getirilerine Ait CCC-GARCH Modeli Sonuçları

\begin{tabular}{|c|l|l|l|l|}
\hline & Katsayllar & Standart Hatalar & $t$-Istatistikleri & Olastlı Değerleri \\
\hline$c_{1}$ & 1296,5121 & 29,1442 & 44,4862 & 0,0000 \\
\hline$c_{2}$ & $-5,5405$ & 5,6458 & $-0,9813$ & 0,3264 \\
\hline$\alpha_{11}$ & 0,0382 & 0,0011 & $34,2876^{*}$ & 0,0000 \\
\hline$\alpha_{12}$ & $-0,0745$ & 0,0036 & $-20,6070^{*}$ & 0,0000 \\
\hline$a_{21}$ & $-0,0757$ & 0,0050 & $-15,0850^{*}$ & 0,0000 \\
\hline$\alpha_{22}$ & 0,1185 & 0,0028 & $42,2892^{*}$ & 0,0000 \\
\hline$b_{11}$ & 0,7690 & 0,0017 & $448,8616^{*}$ & 0,0000 \\
\hline$b_{12}$ & $-0,6922$ & 0,1377 & $-5,0284^{*}$ & 0,0000 \\
\hline$b_{21}$ & 0,8696 & 0,0025 & $352,2192^{*}$ & 0,0000 \\
\hline$b_{22}$ & 0,5705 & 0,0089 & $63,8467^{*}$ & 0,0000 \\
\hline$\theta_{1}$ & 0,3764 & 0,1064 & 3,5372 & 0,0004 \\
\hline$\theta_{2}$ & $-0,0423$ & 0,0011 & $-37,5192$ & 0,0000 \\
\hline
\end{tabular}

Tablo 6'da CBECI ve MOEX enerji endekslerinin getirilerine ait CCC-GARCH modeli sonuçlarına göre, CBECI endeksinden volatilite kalıcılığı hakkında bilgi veren $\alpha_{11}$ ve $b_{11}$ 
parametrelerinden her ikisinin de \%1 anlamlılık düzeyinden istatistiki açıdan anlamlıdır. $\mathrm{Bu}$ iki parametrenin değerleri toplamı 0,79 olduğu ve 1'e yakın olmasından dolayı volatilite kümelemesi olduğu söylenebilir. Ayrıca CBECI endeksinden meydana gelen volatilitenin kalıcılığ1 olduğunu söylemekte mümkündür. $\alpha_{22}$ ve $b_{22}$ parametreleri ise MOEX enerji endeksinin volatilitesinin kalıcılığını ölçmektedir. $\alpha_{22}$ ve $b_{22}$ parametrelerinin her ikisinin de $\% 1$ önem düzeyinde anlamlı olduğu tespit edilmiş ve parametrelerin toplamı 0,68 olarak tespit edilmiştir. Elde edilen bu değerin 1'e yakın olduğu ve volatilite kümelemesi oluştuğu görülmektedir.

MOEX enerji endeksinin volatilitesinden CBECI endeksi volatilitesine doğru olan etkileşimin varlığını ifade eden $\alpha_{12}$ ve $b_{12}$ parametrelerinin her ikisinin de istatistiki açından anlamlı olduğu tespit edilmiştir. Yani MOEX enerjisinin volatilitesini artıran \%1 bir şokun CBECI volatilitesini 0,76 oranında azaltmaktadır. CBECI volatilitesinden MOEX enerji endeksi volatilitesine doğru etkileşimi ölçen $\alpha_{21}$ ve $b_{21}$ parametrelerinin her ikisi de istatistiki açından anlamlıdır. Buna göre CBECI endeksinin volatilitesinden meydan gelen \%1'lik bir şok MOEX enerji endeksi volatilitesini 0,79 oranında artırmaktadır. CBECI ve MOEX enerji endeksleri arasındaki volatil davranışlar dikkate alındığında aralarında çift yönlü volatilite etkileşimi olduğu görülmektedir. Ayrıca CBECI endeksi ile MOEX enerji endeksi getirileri arasındaki sabit koşullu korelasyon ilişkisini açıklayan $\theta_{1}$ ve $\theta_{2}$ parametrelerinin istatistiki açıdan anlamlı olduğu, buna sabit koşullu korelasyonun CBECI endeksinden MOEX enerji endeksine doğru pozitif yönlü ve orta düzeyde kuvvetli, ancak MOEX enerji endeksinden CBECI endeksine doğru negatif yönlü zayıf bir ilişki bulunmaktadır.

\section{Sonuç}

CBECI ile S\&P 500 enerji, SSE enerji ve MOEX enerji endekslerinin arasındaki volatilite etkileşimini incelemek amacıyla CCC-GARCH modeli kullanılmıştır. Çalışma da 22.05.201710.02.2021 dönemini kapsayan haftalık verileri getiri serisine dönüştürülerek kullanılmıştır. Araştırmada elde edilen bulgulara göre; S\&P 500 enerji endeksinden meydana gelen şokların CBECI endeksini artırdığı ancak MOEX enerji endeksinden meydana gelen şokların ise CBECI endeksini azalttığı görülmektedir. CBECI endeksinden SSE enerji ve MOEX enerji endekslerine doğru volatil hareketler olduğu, fakat CBECI endeksinden S\&P 500 enerji endeksine doğru volatilite etkileşimi olmadığı tespit edilmiştir. CBECI ile MOEX enerji endeksi arasında çift yönlü etkileşim olduğu söylenebilir. Ancak CBECI ile S\&P 500 enerji ve SSE enerji endeksleri arasında tek yönlü etkileşim mevcuttur. 
Analizlerden elde edilen bulgulara göre Bitcoin elektrik tüketiminin, ABD ve Rusya'nın enerji şirketi değerlemelerinden etkilendiği sonucuna ulaşılmıştır. Ayrıca Bitcoin elektrik tüketiminin, Rusya ve Çin'in enerji şirketi değerlemelerini etkilemektedir. Elde edilen bu sonuç Rehman ve Kang (2020), Bouri vd. (2017), Symitsi ve Chalvatzis (2018), Baur ve Oll (2019) çalışmalarına paralel sonuçlar elde edilmiştir. Bitcoin elektrik tüketiminin, ABD’nin enerji piyasaları üzerinde bir etkisi olmadığı sonucu elde edilmiştir. ABD enerji piyasaları ve Bitcoin elektrik tüketimi arasında ilişki tespit edilememesinin, ABD enerji sektörünün hakim olduğu birincil enerji kaynaklarının diğer kaynaklara kıyasla elektrik üretiminde daha az kullanılmasından kaynaklanabileceği düşünülmekte; gelecek çalışmalara bu konunun araştırılması önem arz etmektedir.

Araştırmadan elde edilen bulgular politika yapıcılar ve enerji piyasası düzenleme kurum ve kuruluşları, enerji şirketlerinin yönetim ve yatırımcıları, fon ve portföy yöneticileri için önem arz etmektedir. Özellikle elektrik enerjisi üretiminde kullanılan enerji mallarının ticaretinde yoğun faaliyet gösteren piyasalar ile Bitcoin'in elektrik tüketimi arasında tespit edilen volatilite ilişkisi; önemi belirtilen muhataplarının karar alma ve stratejik planlama süreçlerinde riskten korunma ve kaçınmalarında fayda sağlayacağı düşünülmektedir.

Bitcoin'in ilk ortaya çıktığı günden bugüne artarak devam eden enerji tüketiminin, bu çalışmada tespit edilen enerji piyasalarındaki etkisinin gelecekte artması muhtemel görünmektedir. Muhatapların, muhtemel artışla beraber enerji piyasalarının baskı altında kalacağını ve bu durumun istikrarsız bir görünüme neden olabileceğini göz önünde bulundurmaları gerektirmektedir. Ayrıca çalışmada tespit edilen bulgulara dayanarak, enerji sektöründe öncü ülkelerin enerji piyasalarının Bitcoin'in elektrik tüketimini etkilemesinin, Bitcoin arzında enerji piyasalarına bağlılı̆gı ön plana çıkartmaktadır. Bitcoin yatırımcıları, madencilik faaliyeti yürüten ve aracılık hizmeti veren şirketlerin, enerji piyasalarına bağımlı bir arzın mevcut talep ile birlikte fiyat çıktısını etkileyebileceğini, nitekim kazançları üzerinde dolaylı bir risk faktörü oluşacağını varsayılmaktadır. 


\section{KAYNAKÇA}

Baur, D. G. \& Oll, J. (2019). "The (un-)sustainability of bitcoin 1nvestments". Politics \& Energy eJournal, 1-19. doi: $10.2139 /$ ssrn. 3365820

Bollerslev, T. (1990). "Modelling the coherence in short-run nominal exchange rates: a multivariate generalized arch model". The Review of Economics and Statistics, 72(3), 498. doi:10.2307/2109358

Bollerslev, T., Engle, R. F. \& Wooldridge, J. M. (1988). "A capital asset pricing model with time-varying covariances". Journal of Political Economy, 96(1), 116-131. doi:10.1086/261527

Bouri, E., Jalkh, N., Molnár, P. \& Roubaud, D. (2017). "Bitcoin for energy commodities before and after the december 2013 crash: diversifier, hedge or safe haven?". Applied Economics, 49(50), 1-11. doi:10.1080/00036846.2017.1299102

Çarkacioğlu, A. (2016). Kripto-para bitcoin. cbeci.org. (у.y.). 8 Nisan 2021 tarihinde https://cbeci.org adresinden erişildi.

Demirgil, H. \& Kesekler, S. (2019). "Döviz kurlarında oynaklık yayılım etkilerinin mgarch yöntemi ile modellenmesi". Süleyman Demirel Üniversitesi İktisadi ve İdari Bilimler Fakültesi Dergisi, 24(4), 1167-1180.

Delgado-Mohatar, O., Felis-Rota, M. \& Fernández-Herraiz, C. (2019). "The Bitcoin mining breakdown: Is mining still profitable?". Economics Letters, 184, 1-4.

Doruk, Ö. T. (2021). "Döviz Kurunun Enerji Hisse Senetlerine Olan Etkisi: Borsa İstanbul İçin Ampirik Bir Sinama". MANAS Sosyal Araştırmalar Dergisi, 10(3), 1735-1744.

Engle, R. F. \& Kroner, K. F. (1995). "Multivariate simultaneous generalized ARCH". Econometric Theory, 11(1), 122-150.

Gurrib, I. (2019). "Can energy commodities affect energy blockchain-based cryptos?". Studies in Economics and Finance, 36(3), 682-699. doi:10.1108/SEF-10-2018-0313

Gurrib, I., Elsharief, E. \& Kamalov, F. (2020). "The effect of energy cryptos on efficient portfolios of key energy listed companies in the s\&p composite 1500 energy index". International Journal of Energy Economics and Policy, 10(2), 179-193. doi:10.32479/ijeep.8676

Güven, Ö., \& Bulut, Ş. (2021). "Güncel Haliyle Bitcoin ve Piyasadaki Değeri Üzerine Bir İnceleme". TroyAcademy, 6(1), 80-89.

Hepsağ, A. \& Akçalı, B. Y. (2016). "Türk finans piyasasında işlem gören bankalar ile abd finans piyasası arasındaki volatilite etkileşiminin analizi". Avrasya Ekonometri İstatistik ve Ampirik Ekonomi Dergisi, 1(1), 54-72. doi:10.17740/eas.stat.2016-MSEMP-6

Huynh, A. N. C., Duong, D., Burggraf, T., Luong, H. T. T. \& Bui, N. H. (2021). "Energy Consumption and Bitcoin Market". Asia-Pacifc Financial Markets, https://doi.org/10.1007/s10690-021-09338-4

İEA. (2016). Energy, climate change and environment 2016 insights. https://www.iea.org/reports/energyclimate-change-and-environment-2016-insights adresinden erişildi.

Investing.com. (у.y.). 8 Nisan 2021 tarihinde https://tr.investing.com/ adresinden erişildi.

Kamiya, G. (2019). Bitcoin energy use: mined the gap. paris: international energy agent. https://www.iea.org/commentaries/bitcoin-energy-use-mined-the-gap adresinden erişildi.

Rauchs, M., Blandin, A., Dek, A. \& Wu, Y. (2020). Cambridge bitcoin elektrik tüketim endeksi (CBECI). https://cbeci.org/ adresinden erişildi.

Rehman, M. U. \& Kang, S. H. (2020). "A time-frequency comovement and causality relationship between bitcoin hashrate and energy commodity markets". Global Finance Journal, 100576. doi:10.1016/j.gfj.2020.100576

Symitsi, E. \& Chalvatzis, K. J. (2018). "Return, volatility and shock spillovers of bitcoin with energy and technology companies". Economics Letters, 170, 127-130. doi:10.1016/j.econlet.2018.06.012 